\title{
A incidência dos ativos intangíveis nas instituições de ensino superior: uma análise em documentações oficiais
}

\author{
The incidence of intangible assets in higher \\ education institutions: an analysis in official documents
}

\begin{abstract}
Liária Nunes Silva ${ }^{\mathbf{1}}$ - Instituto Federal de Educação, Ciência e Tecnologia do Piauí | São João do Piauí | PI | Brasil. Contato: liaria.nunes@ ifpi.edu.br. ORCID http://orcid.org/0000$\underline{0002-0666-249 X}$
\end{abstract}

\begin{abstract}
Alan Malacarne ${ }^{2}$ - Universidade Federal de Sergipe | São Cristóvão | SE | Brasil. Contato: alanmalacarne1988@gmail.com. ORCID: http://orcid.org/0000-0001-5149-2998
\end{abstract}

Ricardo Fontes Macêdo ${ }^{3}$ - Universidade Federal de Sergipe | São Cristóvão | SE | Brasil.
Contato: ricardo10fontes @ gmail.com. ORCID: http://orcid.org/0000-0002-8316-630X

Robelius De-Bortoli ${ }^{4}$ - Universidade Federal de Sergipe | São Cristóvão | SE | Brasil. Contato: robelius@yahoo.com.br. ORCID http://orcid.org/0000-0003-1231-6451

Resumo: Os ativos intangíveis são importantes fatores de diferenciação e potenciais geradores de benefícios futuros para as instituições, portanto são elementos que devem ser considerados pela gestão das Instituições de Ensino Superior. O objetivo deste estudo é determinar o grau de importância que as Instituições de Ensino Superior dedicam nos relatórios das Comissões Próprias de Avaliação aos fatores classificados como ativos intangíveis. Neste artigo, adotou-se a Teoria Fundamentada em Dados ou Grounded Theory para analisar os documentos institucionais de autoavaliação de Instituições de Ensino Superior, a partir de então os dados coletados foram categorizados como ativos intangíveis segundo a taxonomia proposta por Kayo et al. (2006). Verificou-se que os ativos de relacionamento são os mais negligenciados pelas Instituições de Ensino Superior e que há uma tendência de que os ativos humanos recebam maior atenção nos relatórios. Observa-se que as Instituições de Ensino Superior, independente da organização acadêmica ou categoria administrativa, tratam os ativos intangíveis da mesma forma, apesar de as Universidades Públicas dedicarem maior atenção a esses ativos nos relatórios de Comissões Próprias de Avaliação, se comparada às Instituições Privadas. Pesquisas anteriores discutiram sobre a importância dos ativos intangíveis em Instituições de Ensino Superior, sobretudo os ativos humanos. Neste artigo, formula-se um novo entendimento sobre a gestão dos ativos intangíveis em Instituições de Ensino Superior, polos fomentadores da geração de ativos intangíveis, sobretudo ativos humanos e ativos de inovação.

Palavras-chave: Ativos de inovação. Ativos de relacionamento. Ativos humanos. Ativos estruturais. CPA.

Abstract: The intangible assets are important factors of differentiation and potential generators of future benefits for the institutions, therefore they are elements that must be considered by the management of the Institutions of Higher Education. The objective of this study is to determine the degree of importance that Higher Education Institutions devote in the reports of the Evaluation Committees to factors classified as intangible assets. In this article we adopted the Data Based Theory or Grounded Theory to analyze the institutional documents of self-evaluation of Higher Education Institutions, from then on, the collected data were categorized as intangible assets according to the taxonomy proposed by Kayo et al. (2006). It has been found that relationship assets are the most neglected by higher education institutions and that there is a tendency for human assets to receive more attention in reporting. It is observed that Institutions of Higher Education, regardless of academic organization or administrative category, treat intangible assets in the same way, although Public Universities pay more attention to these assets in the Reports of Own Evaluation Commissions, when compared to Private Institutions. Previous research has discussed the importance of intangible assets in Higher Education Institutions, especially human assets. In this article, a new understanding about the management of intangible assets is formulated in Higher Education Institutions, which are the driving forces behind the generation of intangible assets, especially human assets and innovation assets.

Keywords: Innovation assets. Relationship assets. Human assets. Structural assets. CPA.

- Recebido em: 19 de novembro de 2018 • Aprovado em: 21 de fevereiro de 2020

DOI: http://dx.doi.org/10.1590/S1414-40772020000100005

Este é um artigo publicado em acesso aberto sob uma licença Creative Commons https://creativecommons.org/licenses/by-nc/4.0/ 


\section{Introdução}

O valor de mercado ou intrínseco de uma empresa é medido a partir da contabilização de ativos tangíveis e intangíveis. Estes representam aproximadamente duas partes dos ativos tangíveis (STEWART, 2001). Os ativos intangíveis, mesmo sendo importantes fatores de diferenciação, não recebem a devida atenção quando considerado o valor de uma empresa, mas eles contribuem sobremaneira para a obtenção de importantes vantagens competitivas (KAYO et al., 2006).

Buscando uma definição contábil padrão para os ativos intangíveis, pode-se dizer que eles são potenciais geradores de benefícios futuros para as instituições, diferente das despesas que são pagamentos sem previsão de ganhos futuros (LIM; MACIAS; MOELLER, 2018). Este conceito realça a sua importância e ao mesmo tempo explica as dificuldades das empresas em depositar atenção a eles quando não dedicam um olhar a longo prazo em seu plano estratégico de gestão.

Por outro lado, a maioria dos ativos intangíveis como pesquisa e desenvolvimento $(\mathrm{P} \& \mathrm{D})$, capital organizacional e treinamento, não têm sido tratados como investimentos (NIEBEL; O'MAHONY; SAAM, 2017), tornando-se um diferencial negligenciado pelas empresas. Talvez, isso ocorra devido às dificuldades de visualização dos ganhos futuros que podem resultar dos investimentos nesse tipo de capital. Com uma gestão ética em uma empresa é possível estabelecer um laço cultural entre ativos intangíveis e recursos éticos e sociais, que são gerados coletivamente e mantidos ao longo do tempo (GAMBETTI; MELEWAR; MARTIN, 2017).

Empresas de Base Tecnológica (MARCUZZO; DOS SANTOS; SILUK, 2017) como as Instituições de Ensino Superior (IES) podem usar a produção de ativos intangíveis como uma fonte estratégica de criação de valor e geração de vantagens competitivas, bem como para gerenciar interna e externamente o seu desempenho, convertendo-os, a partir de uma gestão efetiva, em benefícios mercadológicos (SILVEIRA et al., 2017). Porém, deve-se atentar para o estudo de Silva (2017) em relação à visão de curto e médio prazos. Ele aponta que a política de corte de custos pode ser uma estratégia de gestão arriscada. Além disso, o autor indica que normalmente nas IES privadas a geração de lucros se fundamenta em racionar custos, uma estratégia que pode gerar consequências negativas, a exemplo da perda de reputação.

Ao considerar a gestão de IES, os órgãos reguladores oficiais do Brasil instituíram o Sistema Nacional de Avaliação do Ensino Superior (SINAES) (BRASIL, 2004). O SINAES orienta as IES em como manter-se em constante avaliação para a melhoria do desempenho de 
sua função fim, que seria a exploração da oferta de serviços educacionais. Dentre os mecanismos previstos na Lei destaca-se a instituição da Comissão Própria de Avaliação (CPA). A CPA é um colegiado gerenciador do processo de autoavaliação, o qual consiste em avaliar (em cada setor pelos seus componentes ou Público Estratégico) o funcionamento da IES em sua essência que é 'vender' ou ofertar serviço de educação. Ela se constitui em uma ferramenta que deveria preocupar-se muito mais com os ativos intangíveis do que com os tangíveis, pois eles são considerados recursos estratégicos 'ocultos', como uma 'grandeza abstrata' ou 'produto virtual'. Portanto, a identificação e avaliação de seus efeitos é algo que merece ser abordado ou contemplado nos modelos de gestão ou de avaliação do desempenho das IES (PIONTKEWICZ; FREITAS, 2018).

Considerando que as IES são polos geradores de ativos intangíveis por natureza, e por isto representam maior valor intrínseco relativo, seria possível identificar um padrão do seu gerenciamento? Neste caso, a atenção dada a este tipo de ativo é diferente em IES conforme a sua Categoria Administrativa? O grau de importância conferido aos Ativos Intangíveis é semelhante nas diversas organizações universitárias? Desta forma, o objetivo deste estudo é determinar o grau de importância que as IES dedicam nos relatórios das CPAs aos fatores classificados como ativos intangíveis.

\section{Metodologia}

Esta é uma pesquisa utilizando a Teoria Fundamentada em Dados ou Grounded Theory (WIESCHE et al., 2017), metodologia projetada para possibilitar o desenvolvimento de uma teoria indutiva, a partir da análise e interpretação sistemática de dados. A percepção da atenção dedicada aos ativos intangíveis pelas IES, nesta pesquisa, se baseia nas informações extraídas dos relatórios de CPAs.

A seleção dos relatórios de CPAs foi realizada no banco de dados do Google Scholar, a partir da aplicação da expressão de busca 'Relatório CPA'. Como critérios de seleção adotouse o recorte temporal, selecionando relatórios referentes ao ano civil de 2016, publicados em 2017, bem como os aspectos geográficos e categorias administrativas das IES. A amostra foi composta por 15 relatórios de IES, sendo uma Universidade Pública, uma Universidade Privada e uma Faculdade isolada de cada uma das cinco regiões geopolíticas do Brasil - Norte, Nordeste, Sul, Sudeste e Centro-Oeste.

A identificação dos ativos intangíveis nos relatórios observou a taxonomia proposta por Kayo et al. (2006), que os divide em quatro categorias: a) Ativos Humanos (Conhecimento, 
Talento, Capacidade, Habilidade e Experiência dos empregados, Administração superior ou Empregados-chave; b) Ativos de Inovação (Pesquisa e Desenvolvimento, Patente, Fórmulas secretas, Know-how tecnológico); c) Ativos Estruturais (Processos, Software proprietário, Banco de dados, Sistemas de informação, Sistemas administrativos, Inteligência de mercado, Canais de mercado) e d) Ativos de Relacionamento (Marcas, Logos, Trademarks, Direitos autorais, Contratos com clientes, fornecedores, Contratos de licenciamento, franquias; Direitos de exploração mineral, de água).

O reconhecimento dos termos referentes aos ativos intangíveis nos relatórios obedeceu aos seguintes procedimentos: a) primeiramente, elaborou-se um roteiro estruturado destacando a região geopolítica, a organização acadêmica, a categoria administrativa, a sigla da IES e os grupos de ativos humanos, ativos de inovação, ativos estruturais e ativos de relacionamento; b) buscou-se, individualmente, todos os termos de cada um dos grupos de ativos intangíveis nos relatórios; c) logo após, somou-se a frequência de aparição dos termos de cada um dos grupos de ativos intangíveis por IES e extraiu-se a média, obtendo-se um valor representativo para cada grupo; d) na sequência, calculou-se um valor médio para cada grupo de ativos intangíveis por categoria administrativa das IES das cinco regiões geopolíticas; por fim, obteve-se uma média geral para cada grupo de ativos intangíveis por região.

\section{Resultados e discussão}

Reunidos os resultados e agrupados nas quatro categorias de ativos, foram comparadas as Regiões Geopolíticas do Brasil. Na Figura 1 estão representadas as médias de frequência de aparições de palavras relativas aos quatro grupos de ativos intangíveis (ativos humanos, ativos de inovação, ativos estruturais e ativos de relacionamento). Observa-se que os ativos de relacionamento são menos frequentes que os demais nas IES das cinco regiões geopolíticas do Brasil. Além disso, é perceptível a tendência de os ativos humanos apresentarem maior frequência de citações nos relatórios. Esse fenômeno pode ser atribuído ao fato de as IES estarem, vocacionalmente, voltadas para a produção de capital intelectual, um conceito que contempla a formação de capital humano (TODERICIUA; SERBAN, 2015).

A abordagem regional dos grupos de ativos aponta que foi distribuída a liderança das regiões. Com exceção da região Norte, que não liderou qualquer grupo de ativos, todas as regiões, de forma alternada, se destacaram das demais em pelo menos um grupo de ativos, a exemplo do comportamento diferenciado das IES da região Sul em se tratando dos ativos humanos. 
Figura 1 - Resultados médios por Regiões Geopolíticas do Brasil

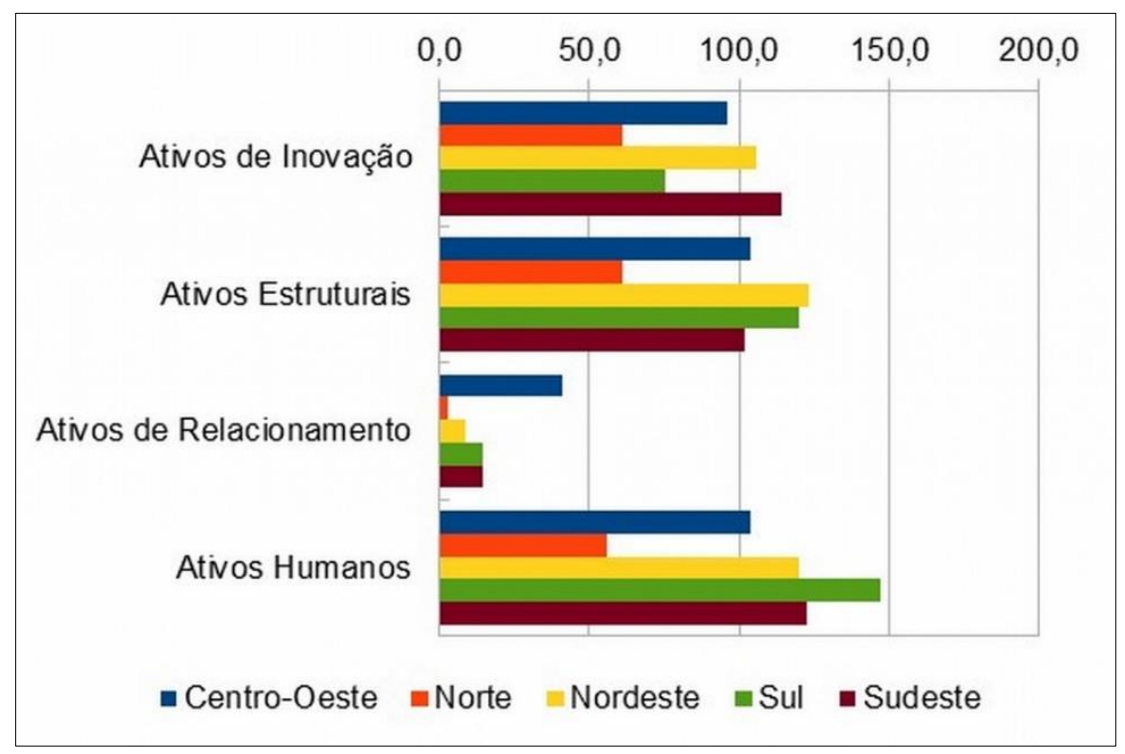

Esses resultados podem ser explicados pelos estudos de Teece (2017), quando afirma que as empresas dedicam maior valor e intensidade em exploração da Propriedade intelectual para atividades inventivas e criativas. Isso pode representar um direcionamento dos esforços da instituição para uma maior produção, ao invés de se empenhar, também, em atividades de registros de identidades visuais (caso da marca) ou de transferências de tecnologias (contratos de licenciamento). Entretanto, os formuladores das políticas estratégicas das IES necessitam compreender a importância da interação entre os vários grupos de ativos intangíveis. Para Chatterjia e Kiranb (2017) quando os ativos de relacionamento complementam os ativos humanos, de inovação e estruturais o seu efeito global no desempenho da instituição é favoravelmente aprimorado.

No caso de marcas, Sinclair e Keller (2017) sugerem que as marcas com vida útil indefinida são adicionadas aos ativos no balanço patrimonial, porém as de vida útil definida não o são. Esse seria um indicativo de que os gestores das IES estudadas (ou os colegiados tipo CPA) não depositam um olhar a longo prazo em suas instituições. Foroudi (2018) destaca que os gestores devem dedicar maior atenção à marca da instituição, pois esta é um ativo intangível que comunica a reputação corporativa global, sendo o primeiro e principal elemento para estabelecer uma relação duradoura com os consumidores, por meio da transmissão de qualidade e credibilidade.

Em relação à região centro-oeste, os ativos de relacionamento estão apresentados na Figura 1 de forma diferenciada, o que remete à busca na base de dados coletados. É possível 
perceber que os resultados da região são consequência exclusivamente da IES de Categoria Administrativa Pública Federal, que apresenta números elevados para o item ‘contratos'. São 112 citações e este número pode ter criado uma falsa interpretação do item.

Também ficou evidente que a Região Norte apresentou valores de referências a ativos intangíveis mais baixos que as demais regiões, assim como as regiões sul e Sudeste apresentaram valores mais elevados. Esse dado pode ser consequência do desenvolvimento regional descrito por Pinto, Rocha e Pirani (2018) quando falam sobre o cenário brasileiro. A Região Norte possui menor Índice de Desenvolvimento Humano Municipal (IDHM) e menor IDHM Rural do Brasil, contrastando com as Regiões Sul e Sudeste. Parece haver uma relação inversa entre IDHM e atenção aos ativos intangíveis dentro das IES.

Os dados também foram analisados conforme a Organização Acadêmica das IES. A Figura 2 apresenta os resultados divididos em Universidade Pública, Universidade Privada e Faculdade isolada, que neste caso são todas privadas. Ficam evidentes os valores mais elevados no tratamento dos ativos intangíveis por parte das Universidades Públicas. As maiores diferenças estão novamente nos ativos de relacionamento, com valores muito baixos para as IES Privadas e Faculdades isoladas.

\section{Figura 2 - Resultados médios de acordo com a Organização Acadêmica das IES}



Perez e Famá (2015) salientam que as economias de escala são substituídas por economias de rede e de relacionamento. Nelas são criadas grandes cadeias de supply chain, inclusive em empresas não industriais. Assim, os ativos intangíveis ganham importância estratégica, pois patentes e marcas geram sólidos relacionamentos. Os resultados demonstrando 
as maiores diferenças no tratamento dado aos ativos de relacionamento entre as diferentes Organizações Acadêmicas analisadas, sugerem que as Universidades Públicas atribuem valor maior a esse grupo de ativos, quando comparadas às Universidades Privadas e Faculdades isoladas. Essa constatação vai de encontro ao comportamento esperado para instituições imersas em um ambiente competitivo e de constantes transformações, como as IES privadas, muitas delas orientadas por princípios racionais, focadas na busca pela eficiência e resultados financeiros elevados (SOARES; LIMA, 2018).

O esperado é que as IES privadas destinassem maior atenção aos ativos de relacionamento, em especial à marca corporativa, um ativo intangível de comunicação, criação de valor e fortalecimento do relacionamento com os diversos stakeholders (RODRIGUES et $a l ., 2017)$. Uma estratégia para enfrentar os desafios e incertezas do "mercado educacional", influenciado pelo número de concorrentes, pelo cenário econômico, bem como pelas políticas educacionais e suas diversas modalidades de ensino (MARINHO; POFFO, 2016).

A Universidade é uma Indústria Criativa (BUAINAIN et al., 2011) por excelência e se direciona aos stakeholders (FREEMAN; REED, 1983), que são elementos essenciais ao planejamento estratégico de negócios. Entre os ativos de relacionamento estão os registros referentes aos direitos do autor, que correspondem a pesquisas, artigos e livros, por exemplo. Os valores percebidos neste campo indicam que possivelmente as universidades privadas e faculdades não dediquem a atenção que merecem esses ativos intangíveis.

Também presentes na categoria dos ativos de relacionamento estão as marcas. A marca está associada com a imagem desejada da IES, quase um portfólio que de alguma forma mantém relação com sua origem. Uma das vantagens de proteger a Marca pode ser percebida quando consideramos a possibilidade real de 'evasão de cérebros ou de tecnologia'. Esta definição surge para indicar que uma Universidade forma ou desenvolve um pesquisador e este migra para outra instituição, estado ou país. Formação de Capital Humano é um ativo intangível desejado pela IES. Quando um pesquisador ou inventor migra de sua origem para desenvolver seu trabalho em outra instituição, na verdade não seria uma perda de um profissional, mas um ganho se considerarmos a Marca da IES formadora que segue. Este valor não costuma ser contabilizado nos balanços patrimoniais.

As políticas de ciência, tecnologia e inovação socialmente referenciadas devem estimular pesquisadores a se vincularem cada vez mais à descoberta do novo. Isto resulta em produção científica e tecnológica que visa cumprir sua função social de ampliação das conquistas sociais da população (NORO; NARVAI, 2018). Talvez os resultados mais elevados 
das IES públicas se devam à missão interna prevista nos documentos reguladores do Ministério da Educação (MEC), que requer qualidade de formação, percebida inclusive nos critérios de ingresso e de elevação na carreira docente.

Quando divididas de acordo com a Organização Acadêmica, os resultados indicam, claramente, diferenças de tratamento dos ativos intangíveis entre as IES. Então, os resultados foram analisados buscando entender sua correlação. Aplicada a Correlação de Pearson (MONCADA, 2005), os resultados indicam que há uma alta correlação entre os resultados das IES, todas acima de 0,93 . Estes resultados sugerem que o tratamento dado pelas IES é o mesmo, diferindo na intensidade tão somente.

A Natureza Jurídica das IES foi considerada para comparar as instituições públicas com as instituições privadas. Na Figura 3 observa-se que as IES públicas, aquelas que subsistem a partir de investimentos públicos, possuem maior frequência de citações de ativos nas quatro categorias. Novamente, percebe-se que os ativos de relacionamento são os menos citados. Outro dado importante é a diferença observada neste grupo de ativos, quando comparado aos demais. Considerando a Natureza Jurídica das IES, observa-se uma relação aproximada de 2x1, no tocante aos ativos de inovação, estrutural e humanos, contudo, com referência aos ativos de relacionamento essa desigualdade totaliza $10 \times 1$.

\section{Figura 3 - Resultados médios de acordo com a Natureza Jurídica das IES}



As IES particulares trataram os ativos intangíveis em seus relatórios de CPA com menor frequência, em comparação com as IES públicas. Os ativos de relacionamento continuam baixos nas IES particulares, quando considerados os ativos intangíveis de inovação, estruturais 
e humanos. Estes valores se repetem em todas as formas de analisar os números coletados. Quando aplicado o Coeficiente de Pearson, os resultados indicam alta correlação de 0,99. Este resultado indica a quase perfeita correlação (SAFRIT, 1990). Estes dados confirmam os anteriores no sentido de que as IES apresentam mesmo perfil, diferindo apenas na intensidade com que tratam os ativos intangíveis.

O fato de as Universidades Públicas apresentarem maior frequência de registros de ativos intangíveis, principalmente de ativos de relacionamento, pode encontrar fundamentação nos programas de fomento governamentais. Perkmann e Walsh (2007) explicam que a política colaborativa de pesquisa é financiada, em grande parte, por programas de políticas públicas. Parece lógico que o controle do investimento público pode ser melhor executado quando o mesmo é direcionado para Instituições públicas.

Em relação aos ativos de inovação, já era previsto que as IES públicas dedicassem maior atenção a eles (SOARES; CUNHA, 2017) se comparadas às IES privadas. Essa supremacia está diretamente relacionada com a abordagem dedicada à pesquisa nessas instituições, explicitada inclusive no princípio constitucional da indissociabilidade entre ensino, pesquisa e extensão (BRASIL, 1988). As universidades públicas, na maioria das vezes, apresentam as condições necessárias para a geração de ativos intangíveis de inovação. Gatti (2017) explica que as universidades públicas apresentam estruturas físicas e capital humano para desenvolverem suas atividades de pesquisas, segundo as vocações ou linhas de pesquisa da instituição.

Além dos instrumentos legais, programas e políticas de incentivos à produção científica em universidades e instituições de pesquisas (TENÓRIO; MELLO; VIANA, 2017), essas IES ainda hospedam a maioria dos cursos de pós-graduação stricto sensu do país, lócus de desenvolvimento sistemático de pesquisas e publicações. De acordo com Vosgerau, Orlando e Meyer (2016), essa produtividade científica mais elevada ocorre também em função das exigências e critérios de avaliação da Coordenação de Aperfeiçoamento de Pessoal de Nível Superior (CAPES).

Para entender se estes dados são consequência da natureza jurídica ou da Categoria Administrativa, as IES particulares foram divididas em privadas com fins lucrativos e privadas sem fins lucrativos. Na Figura 4 observa-se a comparação entre as IES que foram divididas em públicas, privadas com fins lucrativos e privadas sem fins lucrativos. Entre as IES privadas a diferença parece estar principalmente nos ativos de inovação. Neste caso, as IES com fins lucrativos apresentam menores valores de citações em relatórios de suas CPAs para ativos de inovação. 
Figura 4 - Resultados médios de acordo com Categoria Administrativa das IES



Por categoria administrativa se esperava que as instituições com fins lucrativos teriam perfil de maior preocupação com os ativos intangíveis, pois eles compõem a maior parte do valor intrínseco ou de mercado de uma empresa (STEWART, 2001), mas estes dados não se confirmaram. Contrariando a expectativa, os ativos de inovação apresentaram valores mais baixos para as IES Privadas com fins lucrativos.

Nesta pesquisa as IES privadas são representadas por Faculdades (com fins lucrativos) e por Universidades (sem fins lucrativos). Procurando compreender os fatores que provocaram tal diferença no tratamento dos ativos de inovação nas respectivas IES privadas, buscou-se identificar na origem dos processos de credenciamento das instituições os requisitos legais que promovem as diferenças entre essas organizações acadêmicas. De acordo com o Decreto $\mathrm{N}^{\mathrm{o}}$ 9.235/2017, que dispõe sobre o exercício das funções de regulação, supervisão e avaliação das instituições de educação superior e dos cursos superiores de graduação e de pós-graduação no sistema federal de ensino, as IES privadas serão credenciadas originalmente como faculdades e poderão, posteriormente, solicitar a alteração da sua organização acadêmica via processo de recredenciamento, podendo ser enquadrada nas categorias centro universitário ou universidade, desde que atendam aos requisitos determinados pela legislação.

Especialmente para as IES privadas que protocolam um pedido de recredenciamento para alterarem sua organização acadêmica para universidade é necessário, dentre outras obrigações, possuírem programa de iniciação científica com projeto orientado por docentes doutores ou mestres, que pode incluir programas de iniciação profissional ou tecnológica e de 
iniciação à docência; e oferecerem regularmente quatro cursos de mestrado e dois cursos de doutorado reconhecidos pelo MEC (BRASIL, 2017). Analisando tais exigências, que por natureza estimulam a produção científica e tecnológica e, consequentemente, a produção de ativos de inovação dentro da universidade, fica mais fácil compreender o porquê da diferença no tratamento dos ativos de inovação nas diferentes IES privadas, uma vez que as IES de organização acadêmica Faculdade não estão sujeitas a tais obrigações.

Novamente as IES Públicas apresentaram maiores valores nas 4 categorias de ativos intangíveis. De acordo com Lim, Macias e Moeller (2018) esses grupos de ativos apresentam uma relação positiva robusta com a alavancagem financeira da empresa, ainda que não sejam amplamente declarados nas demonstrações financeiras e nos registros regulatórios. Seria esperado que as IES Privadas com fins lucrativos tivessem maior preocupação objetiva em tratar, desenvolver e proteger seus ativos intangíveis, visto que são ativos singulares que representam grande diferencial competitivo (MENDES et al., 2012). Além do que, os investimentos em ativos intangíveis são estratégicos para a melhoria do desempenho financeiro da instituição e criação de valor a longo prazo (TAHAT; AHMED; ALHADAD, 2018).

Em uma análise totalizante dos resultados apresentados, buscou-se um indicativo da existência ou não de uma correlação entre as IES estudadas, considerando as diferenciações de acordo com a Organização acadêmica, Natureza jurídica e Categoria adminstrativa. Quando aplicado o Coeficiente de Pearson, os resultados indicaram uma forte correlação entre as variáveis, com valores superiores a 0,94 nas três relações possíveis. Estes valores reforçam a interpretação de que as IES, independente de sua Organização acadêmica, Natureza jurídica ou Categoria adminstrativa, possuem o mesmo perfil de atenção aos ativos intangíveis produzidos em suas atividades fins, o Ensino, a Pesquisa e a Extensão.

Os resultados apresentados nesta pesquisa sugerem duas hipóteses que merecem ser estudadas com mais profundidade: a primeira é que os dirigentes das IES desconhecem a dimensão de sua produção de ativos intangíveis dentro de uma Instituição de Ensino Superior. A segunda é de que a visão dos dirigentes está voltada para lucros imediatos, dispensando o registro de valores construídos dentro de sua IES, mesmo que de forma aleatória. Nesse sentindo, percebe-se uma lacuna na gestão universitária brasileira. Faltam modelos de gestão com uma abordagem direcionada para a geração, identificação, avaliação e gerenciamento dos ativos intangíveis resultantes das atividades de ensino, pesquisa e extensão. Essa abordagem de gestão universitária requer o desenvolvimento de um Plano de Desenvolvimento Institucional 
e sistemas internos de avaliação que reconheçam a importância dos ativos intangíveis como elementos estratégicos na geração de valor Organizacional.

$\mathrm{Na}$ literatura científica a respeito do tema é possível identificar modelos de gestão de ativos intangíveis em universidades, a exemplos de modelos aplicados em universidades europeias. Ramírez Córcoles (2013) destaca o Observatório de Universidades Europeias, o Programa PCI: Comunidad de Madrid (Espanha) e o Relatório de Capital Intelectual em Universidades Austríacas. De acordo com Cricelli et al. (2018) são modelos focados na geração e gestão eficiente dos ativos intangíveis das universidades.

\section{Conclusões}

Após analisados os resultados, fica evidente que as IES estudadas demonstram um padrão de comportamento em relação ao tratamento dos ativos intangíveis, agrupados em categorias conforme a literatura em que se baseia este estudo. É possível afirmar que todas as IES, de todas as Regiões Geopolíticas do Brasil, de todas as categorias administrativas tratam os ativos intangíveis da mesma forma. $\mathrm{O}$ que as diferenciam é a intensidade/frequência com que os ativos intangíveis são relatados nos relatórios de CPA.

As diferenças percebidas estão centradas nas IES Públicas ou Federais. São Instituições classificadas como Universidades, segundo sua Organização Acadêmica, e possuem compromisso com o desenvolvimento de Ensino, Pesquisa e Extensão. Este tripé é condição e motivo de sua existência. Elas são financiadas com dinheiro público e, talvez por este motivo, dediquem maior atenção aos ativos intangíveis.

As IES de Categoria Administrativa Privadas com fins lucrativos contrariam as expectativas deste estudo em relação ao tratamento dado aos ativos intangíveis, principalmente os de inovação e de relacionamento. As IES particulares, em geral, demonstram dedicar atenção aos ativos intangíveis inversamente ao seu valor expresso na Literatura específica.

Algumas limitações neste estudo podem ser relatadas. A amostra aleatória e pequena sugere que seria interessante buscar uma representatividade maior para futuros estudos para que seja possível inferir os resultados. Além disso, recomenda-se o uso de uma classificação de ativos intangíveis mais alinhada com as atividades desenvolvidas nas universidades, o ensino, a pesquisa e a extensão. 


\section{Referências}

BRASIL. Lei $\mathbf{N}^{\circ} \mathbf{1 0 . 8 6 1}$ de 14 de abril de 2004. Institui o Sistema Nacional de Avaliação da Educação Superior-SINAES e dá outras providências. Brasília, 2004. Disponível em: http://www.planalto.gov.br/ccivil_03/_ato2004-2006/2004/lei/110.861.htm. Acesso em: 25 jul. 2018.

BRASIL. Constituição da República Federativa do Brasil. Brasília, DF: Senado Federal, 1988. Disponível em: https://www2.senado.leg.br/bdsf/bitstream/handle/id/518231/CF88_Livro_EC91_2016.pdf. Acesso em: 2 ago. 2018.

BRASIL. Decreto $\mathbf{N}^{\circ} 9.235$ de 15 de dezembro de 2017. Dispõe sobre o exercício das funções de regulação, supervisão e avaliação das instituições de educação superior e dos cursos superiores de graduação e de pós-graduação no sistema federal de ensino. Brasília, 2017. Disponível em: http://www.planalto.gov.br/ccivil_03/_Ato2015-

2018/2017/Decreto/D9235.htm. Acesso em: 12 jul. 2018.

BUAINAIN, A. M.; MENDES, C. I. C.; SILVA, A. B. O.; CARVALHO, S. M. P. Indústria criativa: direitos de autor e acesso à cultura / Creative Industry: copyrights and access to culture. Liinc em Revista, Rio de Janeiro, v. 7, n. 2, p. 510-537, 2011. Disponível em: http://revista.ibict.br/liinc/article/view/3319. Acesso em: 25 jul. 2018.

CRICELLI, L.; GRECO, M.; GRIMALDI, M.; DUEÑAS, L. P. L. Intellectual capital and university performance in emerging countries: Evidence from Colombian public universities. Journal of Intellectual Capital, Flórida, v. 19, n. 1, p. 71-95, 2018. Disponível em: https://fardapaper.ir/mohavaha/uploads/2019/07/Fardapaper-Intellectual-capital-anduniversity-performance-in-emerging-countries.pdf. Acesso em: 3 ago. 2018.

CHATTERJIA, N.; KIRANB, R. Role of human and relational capital of universities as underpinnings of a knowledge economy: A structural modelling perspective from north Indian universities. International Journal of Educational Development, Amsterdã, v. 56, p. 52-61, 2017. Disponível em: https://ideas.repec.org/a/eee/injoed/v56y2017icp52-61.html. Acesso em: 10 set. 2018.

FOROUDI, P. Influence of brand signature, brand awareness, brand attitude, brand reputation on hotel industry's brand performance. International Journal of Hospitality Management, Amsterdã, v. 5, n. 16, p. 1-15, 2018. Disponível em: https://www.sciencedirect.com/science/article/abs/pii/S0278431917308411: Acesso em: 3 jun. 2018.

FREEMAN, R. E.; REED, D. L. Stockholders and stakeholders: A new perspective on corporate governance. California Management Review, California, v. 25, n. 3, p. 88-106, 1983. Disponível em: https://journals.sagepub.com/doi/abs/10.2307/41165018. Acesso em: 6 jun. de 2018. 
GAMBETTI, R. C.; MELEWAR, T. C.; MARTIN, K. D. Guest Editors' Introduction: Ethical Management of Intangible Assets in Contemporary Organizations. Business Ethics

Quarterly, England, v. 27, n. 3, p. 381-392, 2017. Disponível em:

https://www.cambridge.org/core/journals/business-ethics-quarterly/article/guest-editorsintroduction-ethical-management-of-intangible-assets-in-contemporaryorganizations/8E439286448DA7E4F12E16AC2FB5C8C1. Acesso em: 10 jul. 2018.

GATTI, B. A. Política de ciência e tecnologia e pesquisa em educação. Revista Eletrônica de Educação, São Carlos, v. 11, n. 1, p. 151-164, 2017. Disponível em:

http://www.reveduc.ufscar.br/index.php/reveduc/article/view/2084. Acesso em: 14 jul. 2018.

KAYO, E. K.; KIMURA, H.; MARTIN, D. M. L.; NAKAMURA, W. T. Ativos intangíveis, ciclo de vida e criação de valor. Revista de Administração Contemporânea, Maringá, v. 10, n. 3, p. 73-90, 2006. Disponível em: http://www.scielo.br/scielo.php?pid=S141565552006000300005\&script=sci_abstract\&tlng=pt. Acesso em: 2 ago. 2018.

LIM, S. C.; MACIAS, A. J.; MOELLER, T. Intangible assets and capital structure. SSRN Electronic Journal, Rochester, NY, 2018. Disponível em: https://papers.ssrn.com/sol3/papers.cfm?abstract_id=2514551. Acesso em: 12 jul. 2018.

MARCUZZO, R.; DOS SANTOS, J. R. G.; SILUK, J. C. M. Delineamento para identificação e gerenciamento de ativos intangíveis em empresas de base tecnológica. Revista Científica online-Tecnologia, Gestão e Humanismo, São Paulo, v. 7, n. 1, p. 2017. Disponível em: http://www.fatecguaratingueta.edu.br/revista/index.php/RCO-TGH/article/view/137. Acesso em: 23 set. 2018.

MARINHO, S. V.; POFFO, G. D. Diagnóstico da qualidade em uma IES: a percepção da comunidade acadêmica. Avaliação, Campinas; Sorocaba, v. 21, n. 2, p. 455-477, 2016.

Disponível em: http://www.scielo.br/scielo.php?pid=S141440772016000200455\&script=sci_abstract\&tlng=pt. Acesso em: 15 jul. 2018.

MENDES, E. N.; CERQUEIRA, M. O.; MARQUES, A. V.; VENEROSO, J. A. C. Ativos intangíveis: análise do impacto do grau de intangibilidade nos indicadores de desempenho empresarial. Enfoque: Reflexão Contábil, Maringá, v. 31, n. 1, p. 37-52, 2012. Disponível em: https://www.redalyc.org/pdf/3071/307124722004.pdf. Acesso em: 7 maio 2018.

MONCADA, J. Estadística para ciencias del movimiento humano. San José: CR Editorial de la Universidad de Costa Rica, 2005.

NIEBEL, T.; O'MAHONY, M.; SAAM, M. The contribution of intangible assets to sectoral productivity growth in the EU. Review of Income and Wealth, Ontário v. 63, p. S49-S67, 2017. Disponível em: https://onlinelibrary.wiley.com/doi/full/10.1111/roiw.12248. Acesso em: 13 jul. 2018.

NORO, L. R. A.; NARVAI, P. C. Produzir conhecimento significativo na área da saúde em tempos de crise: inviável ou quase impossível? Revista Ciência Plural, Natal, v. 4, n. 1, p. 46, 2018. Disponível em: https://periodicos.ufrn.br/rcp/article/view/14797. Acesso em: 15 jul. 2018. 
PEREZ, M. M.; FAMÁ, R. Características estratégicas dos ativos intangíveis e o desempenho econômico da empresa. Unisanta Law and Social Science, São Paulo, v. 4, n. 2, p. 107-123, 2015. Disponível em: https://ojs.unisanta.br/index.php/lss/article/view/393. Acesso em: 13 set. 2018.

PERKMANN, M.; WALSH, K. University-industry relationships and open innovation: Towards a research agenda. International Journal of Management Reviews, UK, v. 9, n. 4, p. 259-280, 2007. Disponível em: https://onlinelibrary.wiley.com/doi/pdf/10.1111/j.14682370.2007.00225.x. Acesso em: 28 set. 2018.

PINTO, C. V. D. S.; ROCHA, B. N.; PIRANI, N. D. C. Indicadores sociais e desenvolvimento rural: um estudo sobre o índice de desenvolvimento humano municipal rural no Brasil. Boletim Regional, Urbano e Ambiental, Brasília, v. 18, jan./jun. 2018. Disponível em:

https://www.ipea.gov.br/portal/images/stories/PDFs/boletim_regional/180618_brua_18_ensai o08.pdf. Acesso em: 30 jul. 2018.

PIONTKEWICZ, R.; FREITAS, M. C. D. Pré-requisitos necessários para um sistema de informação contábil realizar a gestão do capital intelectual. Revista Tecnologia e Sociedade, Curitiba, v. 14, n. 31, p. 171-188, 2018. Disponível em:

https://periodicos.utfpr.edu.br/rts/article/view/7023. Acesso em: 15 jul. 2018.

RAMÍREZ CÓRCOLES, Y. Intellectual capital management and reporting in European higher education institutions. Intangible Capital, España, v. 9, n. 1, p. 1-19, 2013.

Disponível em: http://www.intangiblecapital.org/index.php/ic/article/view/201/297. Acesso em: Acesso em: 22 jul. 2018.

RODRIGUES, J.; MIYAHIRA, N. N.; NASCIMENTO, FERNANDO.; MARINHO, B. L. Por que marcas corporativas? A percepção de executivos brasileiros sobre os motivos para adotar corporate branding. REAd - Revista Eletrônica de Administração, Porto Alegre, v. 23, p. 232-261, 2017. Disponível em: http://www.scielo.br/scielo.php?pid=S1413$23112017000400232 \&$ script=sci_arttext\&tlng=pt. Acesso em: 2 jul. 2018.

SAFRIT, M. J. Introduction to measurement in physical education and exercise science. St Louis: C.V. Mosby Company, 1990.

SILVA, C. M. M. Gestão do capital intelectual e dos ativos intangíveis para geração de valor em instituições de ensino superior privadas no Brasil. 2017. 143 f. Tese (Doutorado em Administração) - Universidade do Grande Rio, Rio de Janeiro, 2017. Disponível em: http://tede.unigranrio.edu.br/handle/tede/191. Acesso em: 28 jul. 2018.

SILVEIRA, S. K. R.; SCHNORRENBERGER, D.; GASPARETTO, V.; LUNKES, R. J. Abordagens de avaliação de ativos intangíveis: uma revisão da literatura. Revista Catarinense da Ciência Contábil, Santa Catarina, v. 16, n. 47, p. 9-25, 2017. Disponível em: http://revista.crcsc.org.br/index.php/CRCSC/article/view/2258. Acesso em: 18 set. 2018.

SINCLAIR, R.; KELLER, K. L. Brand value, accounting standards, and mergers and acquisitions: "The Moribund Effect". Journal of Brand Management, Switzerland, v. 24, n. 2, p. 178-192, 2017. Disponível em: https://link.springer.com/article/10.1057/s41262-0160025-1. Acesso em: 1 jul. 2018. 
SOARES, T. C.; LIMA, M. A. Managerialism nas instituições de ensino superior brasileiras. Revista Ciências Administrativas ou Journal of Administrative Sciences, Fortaleza, v. 24, n. 2, p. 1-13, 2018. Disponível em: https://periodicos.unifor.br/rca/article/view/7183. Acesso em: 2 set. 2018. SOARES, R. S.; CUNHA, M. I. Qualidade do ensino de graduação: concepções de docentes pesquisadores. Avaliação, Campinas; Sorocaba, v. 22, n. 2, p. 316-331, 2017. Disponível em: http://www.scielo.br/pdf/aval/v22n2/1982-5765-aval-22-02-00316.pdf. Acesso em: 1 jul. 2018.

STEWART, T. A. The wealth of knowledge: Intellectual capital and the twenty-first century organization. New York: Crown Business, 2001.

TAHAT, Y. A.; AHMED, A. H.; ALHADAB, M. M. The impact of intangibles on firms' financial and market performance: UK evidence. Review of Quantitative Finance and Accounting, Switzerland, v. 50, n. 4, p. 1147-1168, 2018. Disponível em: https://link.springer.com/article/10.1007/s11156-017-0657-6. Acesso em: 25 jun. 2018.

TEECE, D. J. Short Note on Intangible Assets, Intellectual Capital, \& the Mission \& Focus of the Tusher Center. University of California, Berkeley, p. 1-8, 2017. Disponível em: https://businessinnovation.berkeley.edu/wp-content/uploads/2017/08/Tusher-CenterPresentation-No.-4.July-2017.pdf. Acesso em: 19 ago. 2018.

TENÓRIO, M.; MELLO, G. A.; VIANA, A. L. D’A. Políticas de fomento à ciência, tecnologia e inovação em saúde no Brasil e o lugar da pesquisa clínica. Ciência \& Saúde Coletiva, Rio de Janeiro, v. 22, n. 5, p. 1441-1454, 2017. Disponível em: https://www.scielosp.org/article/csc/2017.v22n5/1441-1454/. Acesso em: 25 ago. 2018.

TODERICIUA, R.; SERBAN, A. Intellectual Capital and its Relationship with Universities. Procedia Economics and Finance, Amsterdã, v. 27, p. 713-717, 2015. Disponível em: https://www.sciencedirect.com/science/article/pii/S2212567115010527. Acesso em: 13 jun. 2018.

VOSGERAU, D. S. R.; ORLANDO, E. A.; MEYER, P. Produtivismo acadêmico e suas repercussões no desenvolvimento profissional de professores universitários. Revista Educação \& Sociedade, Campinas, v. 38, n. 138, p. 1-17, 2016. Disponível em: http://www.scielo.br/scielo.php?pid=S010173302017005001102\&script=sci_arttext\&tlng=pt. Acesso em: 1 ago. 2018.

WIESCHE, M.; JURISCH, M. C.; YETTON, P. W.; KRCMAR, H. Grounded Theory methodology in information systems research. MIS Quarterly, Australia, v. 41, n. 3, p. 685701, 2017. Disponível em: http://dro.deakin.edu.au/eserv/DU:30105882/yettongroundedtheory-2017.pdf. Acesso em: 8 set. 2018. 